\section{Diversity, Not Divisiveness, Is the Future of Nuclear Medicine}

TO THE EDITOR: I am writing with regard to the article "The Standard of Care: From Nuclear Radiology to Nuclear Medicine," by Johannes Czernin, in the May 2020 edition of The Journal of Nuclear Medicine (JNM) (1). In this article, Dr. Czernin speaks to the rapidly evolving future of our specialty in an era of tremendous progress, especially in the area of theranostics. Unfortunately, in introducing "The Standard of Care" series as a recurring feature that will highlight exciting developments in our field, Dr. Czernin has chosen to focus on drawing an artificial and unnecessary distinction of moving from "Nuclear Radiology" to "Nuclear Medicine" rather than on the scientific progress that our community as a whole is making. Dr. Czernin even makes the startling observation that the new series will "promote our reintegration into medicine." On the contrary, it seems to me that we never left.

This is not the first time that Dr. Czernin has used his platform as editor of $J N M$ to advocate a move away from radiology and toward a model closer to that in Europe, where nuclear medicine has evolved as more of an independent specialty. In multiple articles he has written since he became editor, he seems to hold radiology responsible for the fact that nuclear medicine does not typically function as an independent specialty in the United States, rather than seeing it as a vibrant and integral part of the broader nuclear medicine community $(2,3)$.

In the more than $30 \mathrm{y}$ that I have been a part of the nuclear medicine and radiology communities, I have frequently been struck by how destructive the internecine squabbling between nonradiologist nuclear medicine physicians and radiologists has been to our field. A variant of the same turf battle also resulted in a highly unfortunate schism between cardiology and the nuclear medicine community. Bringing up tired stereotypes of the perceived deficiencies of radiologists or nonradiologist nuclear medicine physicians only defeats the broader goal of bringing as many qualified and enthusiastic practitioners to our specialty as possible.

The optimal structure for training in nuclear medicine has been and remains a controversial topic that task forces from multiple organizations have discussed over many years. The current diversity of training pathways has its limitations, but it also brings a diversity of practicing physicians to our specialty, each with different strengths and skills and each necessary to meet expected future growth in nuclear medicine. One size does not fit all.

One of the things that makes nuclear medicine so unique is the breadth of specialties and expertise that comprise the nuclear medicine community. Within the physician ranks, nuclear medicine physicians, radiologists, cardiologists, endocrinologists, and a variety of others have made essential contributions to our field and continue to advance the science and clinical practice of nuclear medicine. In addition, a wide variety of nonphysician members of the community including technologists, physicists, radiopharmacists, basic scientists, and members of industry are crucial to the

COPYRIGHT @ 2020 by the Society of Nuclear Medicine and Molecular Imaging. advancement of our specialty. By embracing the diversity of the contributors to our field rather than singling out those who have a different background from our own, we stand the best chance of moving nuclear medicine to greater heights in the future.

A recent Newsline article by Society of Nuclear Medicine and Molecular Imaging President Vasken Dilsizian (4) summarizes our strength through diversity: "The field of nuclear medicine and molecular imaging crosses many boundaries; among branches of science such as physics, biology, and chemistry; among disease areas such as oncology, neurology, and cardiology; and among modalities, with fusion imaging. SNNMI mirrors that amalgamation, unique among nuclear medicine societies in its inclusion of all nuclear medicine professionals." Rather than dividing practitioners into opposing camps, our specialty and the editor of our main journal should recognize the beauty of our diverse community and foster collaboration and scientific excellence among all of our community members. In beginning a new series on progress in nuclear medicine, perhaps Dr. Czernin should concentrate on the scientific advances that can move our entire community forward rather than the differences that can drive us apart.

\section{REFERENCES}

1. Czernin J. The standard of care: from nuclear radiology to nuclear medicine. J Nucl Med. 2020;61:637.

2. Czernin J, Sonni I, Razmaria A, Calais J. The future of nuclear medicine as an independent specialty. J Nucl Med. 2019;60(suppl 2):3S-12S.

3. Czernin J. Toward independent nuclear medicine, molecular imaging, and theranostic programs. J Nucl Med. 2019;60:1037.

4. Dilsizian V. SNMMI leadership update: focus on international diversity and inclusivity. J Nucl Med. 2019;60:21N.

Richard B. Noto
Rhode Island Hospital/Warren Alpert Medical School of
Brown University
593 Eddy St.
Providence, RI 02903
E-mail: RNoto@lifespan.org

Published online Jun. 23, 2020.

DOI: $10.2967 /$ jnumed.120.250035

REPLY: I greatly appreciate Dr. Noto's comments about my editorial entitled, "The Standard of Care: from Nuclear Radiology to Nuclear Medicine" (1). The Journal of Nuclear Medicine $(J N M)$ is a great forum for debates about our field. I respect Dr. Noto's point of view, which many others may share.

I completely agree with the notion that diversity, not divisiveness, is the future of nuclear medicine. It is correct that I sometimes use the $J N M$ platform to advocate for the independence of nuclear medicine toward a model closer to that in Europe (2). However, it is incorrect that I hold radiology responsible for nuclear medicine's lack of independence. This responsibility is 